Research Paper

\title{
Development of industrial lands and influencing factors towards new economic strategies in China
}

\author{
Analysis based on Panel Regressions \\ Jiahui XU, Tsinghua University, China \\ Song CHEN, Tsinghua University, China \\ Taofang YU,Tsinghua University, China
}

\begin{abstract}
Industrial lands in China deserve new investigation as China is transferring from the highspeed development mode into new normal economy stage. We measured the development of industrial lands in China in the past two decades. Using urban industrial-construction proportion and location quotient for industrial lands (LQ) as indicators, we found that: (1) Industrial lands were generally growing slower than construction lands, and the national proportion decreased to about 20\%; (2) Hot spot provinces, with a LQ above 1, and hot spot capital cities, with a proportion above $20 \%$, were concentrating to eastern regions. After building panel data based on 25 capital cities in 6 years that cover the past two decades, we conducted regressions in different regions and periods. Generally, economic development was significantly and strongly influential to proportions. Industry structures in terms of both second and tertiary industry show negative relationships in the second decade.Industrial land prices were positive related to proportions in eastern regions but negative related in central and western China. Unexpected findings include the negative coefficient of foreign investment and fiscal expenditures on technology and education. Our study provides new investigation of industrial lands towards new development stage and helps raise understanding of factors influencing industrial lands in developing countries.
\end{abstract}

\section{Keywords}

Industrial lands, Economic transformation, Panel data regression, China

\section{Introduction}

Industrial lands function as the most basic and fundamental natural resource for production activities(Yang et al.,2019; Zhang et al.,2019).To developing counties, industrial lands are attached with more importance.Among the developing world, China has achieved unbelievable and dramatic urbanization and industrialization progress in the past decades, accompanied with expansions of industrial lands(Wu et al.2014; Qiu et al.,2019). The economic transformation marked by the reform and opening-up is the start of the high-speed, factor-intensive development pattern: the relationship between industrialization and urbanization is uncoordinated; the motivator for economic growth is insufficient and unsustainable(He et al.,2014; Wu et al.,2016).To solve the issues embedded in the previous pattern, another economic transformation began in 2011, marked as the "new normal" economic: the growth rate is slower; the industry structure is upgrading; and the motivator would be innovation and technology. In the former development stage, industrial lands are typically extensive and incremental(Shu and Xiong,2019).How did the industrial lands develop and change after the transformation in 2011? What are the differences between industrial lands pattern in the previous development mode and the new one? Besides, does the transformation help solve the incremental industrial land use? What factors actually influence industrial lands? 
This paper aims to measure the development of urban industrial lands in the past two decades and analyze how various factors are related to industrial lands towards new development stage with panel regressions. The paper is organized as follows: Chapter 2 presents the literature review about industrial lands development in China and the influencing factors that characterize the economic transition. Chapter 3 introduces data sources. Chapter 4 measures the development of urban industrial lands and uses indicators to describe the difference among provinces and regions. Chapter 5 presents the findings of different panel regressions about the influencing factors. Chapter 6 presents findings and discussions and Chapter 7 draws conclusions.

\section{Literature Review}

\subsection{Understanding Urban Industrial lands in China}

A dramatic increase of industrial lands in China since the reform and opening-up was documented before. Previous studies argued that industrial lands were crucial to urban growth and economic development in China(Qiu et al.,2015; Yue et al.,2013). In the classical Cobb-Douglas function model, capital and labor are included as production factors, and technology influences the production capacity. What role does industrial land play? According to Needham et al.(2013), lands play an substituting role for labor and capital. In reality, land is viewed as a production factor together with capital and labor in China. Mao and Zuo(2007) indeed carried out an empirical research by introducing lands as a production factor into CobbDouglas function model,and the results confirmed the importance of industrial lands.

However,recent studies are claiming that industrial lands in China are inefficient in productivity and land use intensity(Gao and Ma,2015;Chen et al.,2019) and disproportional in terms of land use structure(Cai et al.,2011).The high industrial-construction proportions in many Chinese cities are seen as reflections of unhealthy land use structure and industry structure(Liu and Zhu,2012).Besides, potential health and pollution risks and disability to create great economic outputs and bid for the central locations are contributing to the reducing of industrial lands (Wu et al.,2018).The change of attitudes suggest that careful review and investigation of industrial lands in the new decades are meaningful.

\subsection{Identifying Influencing factors on Industrial lands}

Among all possible factors,economic development is considered the most powerful influencing factor for land expansion(Xie et al.,2016).Currently,economical transformation of China from a high-speed and factor-intensive growth pattern into an innovation-motivated one would affect the land use pattern including industrial lands(He et al.,2014).

During the former high-speed development stage,the importance of globalization,industrialization and economic incentives were stressed. Globalization is viewed to have greatly driven the expansion of urban industrial lands among the academia(Huang et al.,2015;Li et al.,2020).Motivated by considerable potential economic revenues,local authorities established lots of industrial parks and expanded industrial lands; the so-called "zone fever" lead to extensive expansions of industrial lands(Wei,2012; Huang et al., 2020; Huang et al.,2020).The base price for industrial lands was kept at a relatively low level by the local governments,which intensified the expansion of industrial zoned areas(Yue et al.,2013;Wu et al.,2014;Zheng et al.,2014)).Different evidences from Singapore suggest that industrial lands prices determined by markets in Singapore have been rising even faster than economic growth rate, which sort of influenced industry development there(Zhu,2000).

Towards the new normal economy, the change of industry structure and technology would influence industrial land use.The coming of post-industrial society by Bell(1974) pointed out that post-industrial society would have decreasing reliance on manufacturing sectors and more reliance on service 
sectors, which would be reflected on land use. Besides,consider the change of growth motivator.An economy normally evolves from labor-intensive to capital-intensive and afterwards technologyintensive(Yang et al.,2019;lammarino and McCann,2006). The productivity differences caused by new technologies bring differences in total productivity and the factor utilization efficiency(Qu et al.,2019), which consequently spurs different demands for lands and space.Take Beijing for example, the integrating of industry structure and widespread of technology have a negative influence on the industrial land supply market(Wen et al.,2017). These economic factors are thought to motivate the reuse or decrease of industrial lands.

\section{Data sources}

Lots of researches have examined the expansion of industrial lands since the reform and opening-up in the last century. To give a new understanding for this century, we carry out analysis at national and provincial levels in the past two decades in the 21th century.

The land use data is based on the Urban Construction Statistical Yearbooks published by the Ministry of Housing and Urban-Rural Development of the People's Republic of China.The yearbooks provide land use utilization data at both provincial and prefecture level. We use the data from 2002 to 2017 to reveal the development of industrial lands.We also select data from the Urban Statistical Yearbooks in corresponding years for regressions.The Urban Statistical Yearbooks, published by National Bureau of Statistics every year, provide social and economic performance data.

\section{Development and Spatial pattern of Urban Industrial lands in China}

\subsection{The national development of urban industrial lands}

From 2002 to 2017, national urban industrial lands generally increased together with the expansion of urban construction lands(Figure 1).The aggregate areas of industrial lands expanded by about $90 \%$ :from 576.89 thousand ha to 1108.37 thousand ha, while the aggregate areas of urban construction lands in China doubled from 2683.26 thousand ha to 5515.547 thousand ha. The industrial-construction proportion (proportion for short) was calculated to measure how much proportion do industrial lands account for the aggregate areas of construction lands.

$$
\text { PROPORTION }_{\mathrm{i}}=\text { IndustrialLand }_{i} / \text { ConstructionLand }_{i}
$$

Generally, the proportion decreased with fluctuations from 2002 to 2017: from $21.5 \%$ to $20.1 \%$.The proportions in the first decades were generally greater than $21 \%$, and even reached the peak amount of $22.28 \%$ in 2009.The second decade witnessed a sharp decrease from the beginning. Afterwards, the proportion stayed at approximately $20 \%$ with slight fluctuations. In conclusion, the national urban industrial lands were expanding, but at a growth rate lower than the rate of construction lands. The industrial-construction proportion, as a reflection of land structure, generally decreased and stayed at around $20 \%$ with slight rises and falls. 


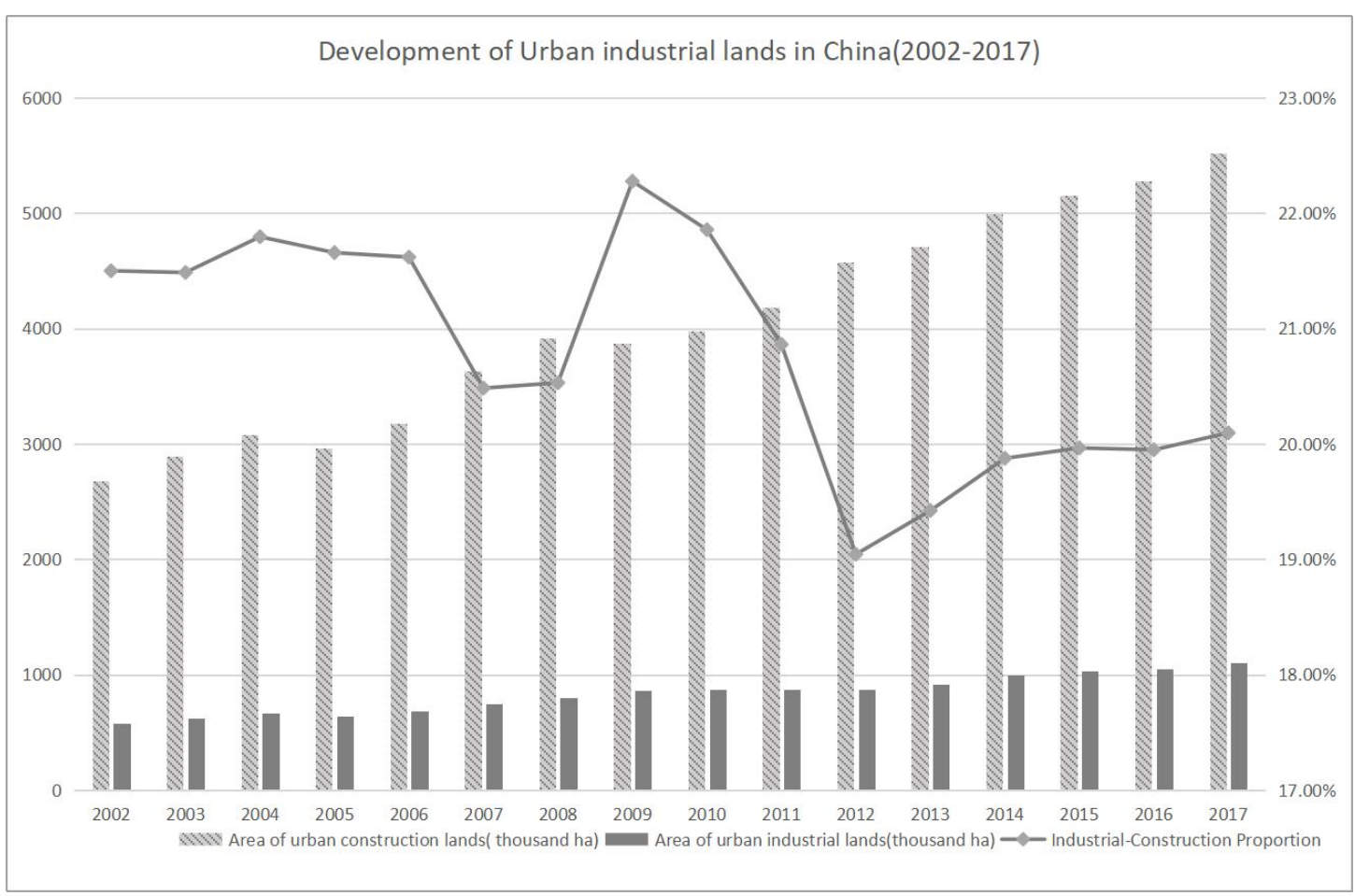

Figure 1.Development of urban industrial lands in China from 2002 to 2017.Source:Calculated and drawn by the authors.

\subsection{Industrial land use at provincial levels}

We examine industrial land use at the provincial level in 2002 and 2017.To reflect the development and expansion of industrial lands, attention is paid to the total area, the industrial-construction proportion as well as a location quotient of lands. At the provincial level, the location quotient of industrial lands (LQ for short) to measure the concentration of industrial lands among provinces is built in reference to the location quotient of industry.

$$
\mathrm{LQ}_{\mathrm{i}}=\frac{\text { IndustrialLand }_{i} / \text { ConstructionLand }_{i}}{\sum \text { IndustrialLand }_{i} / \sum \text { ConstructionLand }_{i}}
$$

From 2002 to 2017, most provinces show an increase of areas of industrial lands. Considering the different total areas of provinces, the value of proportion and LQ would be more useful. There are apparent differences among different provinces. Great differences exist among eastern regions, central regions and western regions (Figure 2,Figure 3,Figure 4).Compared to the national proportions, the value of proportions were generally higher in eastern provinces, and lower in western provinces. Temporal changes also differ among regions. Most central and western provinces generally showed a decline of amount of proportion, while half of eastern provinces showed an increase.

The values of LQ help us identify the provinces with higher proportion than the national value and select the hot spot provinces. From 2002 to 2017, the maximum of LQ increased from 1.22 to 1.43 while the minimum value declined from 0.66 to 0.33 . This suggested that provinces were evolving in disparate ways and the value of range was increasing. We also selected provinces with a LQ above 1 to define the hot spot provinces. In 2002, 15 provinces were selected:7 provinces in eastern China, 6 in central China and 2 in western China. In 2017, only 9 provinces were selected, and 7 of them were located in eastern China. 
The change of top 5 provinces in terms of industrial-construction proportion provide evidences in correspondence with the economic transformation(Table 2).Provinces as historical basements for heavy industries had high proportions in 2002, but in 2017, most provinces ranking top 5 were located in eastern regions. Eastern provinces were given preference and more benefits for economic development, and became the base for light manufacture. Therefore, they generally showed high proportion at the end with continual increases.

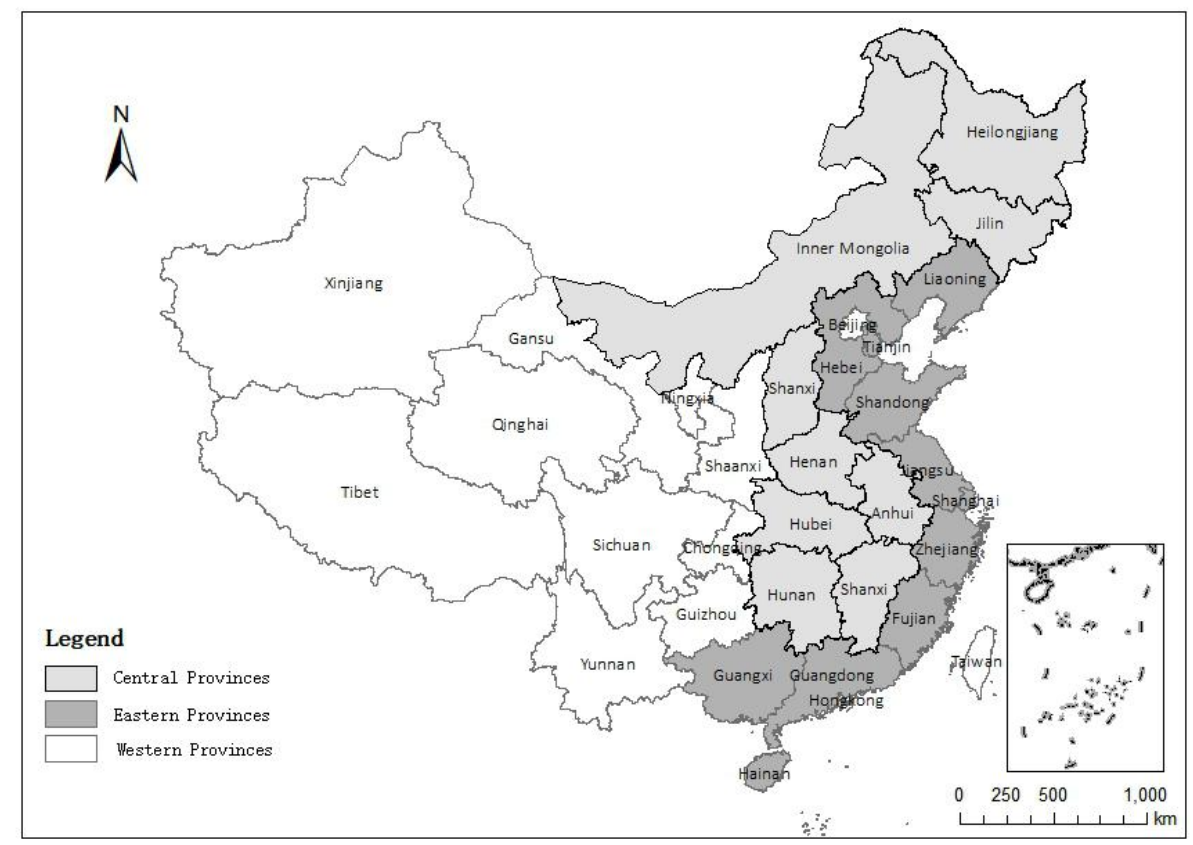

Figure 2.Provincial units of Central,Eastern and Western China. Source:compiled and drawn by the authors using ArcMap 10.5.

\begin{tabular}{|c|c|c|c|c|c|c|c|}
\hline \multicolumn{2}{|c|}{ Urban industrial lands } & \multicolumn{2}{|c|}{ Areas(unit: thousand ha) } & \multicolumn{2}{|c|}{ Proportion } & \multicolumn{2}{|c|}{ LQ } \\
\hline & & 2002 & 2017 & 2002 & 2017 & 2002 & 2017 \\
\hline \multicolumn{2}{|c|}{ Whole Nation } & 576.89 & 1108.37 & $21.50 \%$ & $20.10 \%$ & - & - \\
\hline \multirow{12}{*}{$\begin{array}{l}\text { Eastern } \\
\text { China }\end{array}$} & Beijing & 16.28 & 26.31 & $15.61 \%$ & $17.95 \%$ & 0.73 & 0.89 \\
\hline & Tianjin & 10.65 & 24.25 & $23.45 \%$ & $24.37 \%$ & 1.09 & 1.21 \\
\hline & Hebei & 22.72 & 27.40 & $21.79 \%$ & $13.60 \%$ & 1.01 & 0.68 \\
\hline & Liaoning & 40.60 & 71.93 & $24.01 \%$ & $26.17 \%$ & 1.12 & 1.30 \\
\hline & Shanghai & 47.03 & 55.06 & $25.78 \%$ & $28.82 \%$ & 1.20 & 1.43 \\
\hline & Jiangsu & 47.88 & 106.48 & $26.29 \%$ & $24.03 \%$ & 1.22 & 1.20 \\
\hline & Zhejiang & 26.23 & 58.85 & $22.73 \%$ & $21.94 \%$ & 1.06 & 1.09 \\
\hline & Fujian & 10.22 & 27.60 & $20.91 \%$ & $18.74 \%$ & 0.97 & 0.93 \\
\hline & Shandong & 41.35 & 102.50 & $21.84 \%$ & $21.99 \%$ & 1.02 & 1.09 \\
\hline & Guangdong & 49.98 & 148.80 & $19.68 \%$ & $26.68 \%$ & 0.92 & 1.33 \\
\hline & Guangxi & 12.95 & 22.05 & $20.34 \%$ & $16.07 \%$ & 0.95 & 0.80 \\
\hline & Hainan & 1.87 & 1.70 & $12.96 \%$ & $6.62 \%$ & 0.60 & 0.33 \\
\hline
\end{tabular}




\begin{tabular}{|c|c|c|c|c|c|c|c|}
\hline \multirow{9}{*}{$\begin{array}{l}\text { Central } \\
\text { China }\end{array}$} & Shanxi & 63.43 & 14.33 & $23.81 \%$ & $12.57 \%$ & 1.11 & 0.63 \\
\hline & Inner Mongolia & 59.81 & 16.14 & $19.38 \%$ & $13.42 \%$ & 0.90 & 0.67 \\
\hline & Jilin & 73.80 & 28.68 & $21.27 \%$ & $20.38 \%$ & 0.99 & 1.01 \\
\hline & Heilongjiang & 126.84 & 35.77 & $19.40 \%$ & $19.73 \%$ & 0.90 & 0.98 \\
\hline & Anhui & 94.89 & 37.07 & $21.47 \%$ & $18.52 \%$ & 1.00 & 0.92 \\
\hline & Jiangxi & 54.68 & 27.75 & $23.23 \%$ & $19.79 \%$ & 1.08 & 0.98 \\
\hline & Henan & 114.97 & 38.64 & $21.92 \%$ & $15.27 \%$ & 1.02 & 0.76 \\
\hline & Hubei & 133.88 & 57.38 & $21.41 \%$ & $22.96 \%$ & 1.00 & 1.14 \\
\hline & Hunan & 92.32 & 23.97 & $21.50 \%$ & $14.65 \%$ & 1.00 & 0.73 \\
\hline \multirow{10}{*}{$\begin{array}{l}\text { Western } \\
\text { China }\end{array}$} & Chongqing & 38.59 & 24.46 & $19.15 \%$ & $20.16 \%$ & 0.89 & 1.00 \\
\hline & Sichuan & 113.35 & 45.08 & $21.92 \%$ & $16.95 \%$ & 1.02 & 0.84 \\
\hline & Guizhou & 35.08 & 15.52 & $20.48 \%$ & $16.42 \%$ & 0.95 & 0.82 \\
\hline & Yunnan & 34.29 & 12.26 & $14.05 \%$ & $11.27 \%$ & 0.65 & 0.56 \\
\hline & Tibet & 7.20 & 1.48 & $9.8 \%$ & $11.84 \%$ & 0.46 & 0.59 \\
\hline & Shaanxi & 49.94 & 14.60 & $17.37 \%$ & $11.87 \%$ & 0.81 & 0.59 \\
\hline & Gansu & 40.30 & 17.14 & $22.83 \%$ & $19.90 \%$ & 1.06 & 0.99 \\
\hline & Qinghai & 9.84 & 1.32 & $15.65 \%$ & $7.40 \%$ & 0.73 & 0.37 \\
\hline & Ningxia & 15.00 & 4.26 & $18.89 \%$ & $10.58 \%$ & 0.85 & 0.53 \\
\hline & Xinjiang & 51.74 & 19.61 & $15.81 \%$ & $15.93 \%$ & 0.74 & 0.79 \\
\hline
\end{tabular}

Table 1.Urban industrial lands of provinces in China(2002,2017).Source: Calculated and compiled by the authors.

\begin{tabular}{cccccc}
\hline Year & Rank 1st & Rank 2nd & Rank 3rd & Rank 4th & Rank 5th \\
\hline $\mathbf{2 0 0 2}$ & Jiangsu & Shanghai & Liaoning & Chengdu & Shanxi \\
& $(0.263)$ & $(0.258)$ & $(0.240)$ & $(0.239)$ & $(0.229)$ \\
2006 & Zhejiang & Jiangsu & Liaoning & Chengdu & Jilin \\
& $(0.278)$ & $(0.277)$ & $(0.238)$ & $(0.228)$ & $(0.229)$ \\
2008 & Jiangsu & Zhejiang & Guangdong & Liaoning & Fujian \\
& $(0.277)$ & $(0.264)$ & $(0.258)$ & $(0.235)$ & Tibet \\
2011 & Jiangsu & Zhejiang & Chongqing & Liaoning & $(0.226)$ \\
& $(0.254)$ & $(0.253)$ & $(0.234)$ & $(0.232)$ & Liaoning \\
2014 & Guangdong & Shanghai & Zhejiang & Tianjin & $(0.233)$ \\
& $(0.254)$ & $(0.252)$ & $(0.242)$ & $(0.236)$ & Jiangsu
\end{tabular}

Table 2.Provinces ranked top 5 for industrial-construction proportion in China. Source:Calculated and complied by the authors 


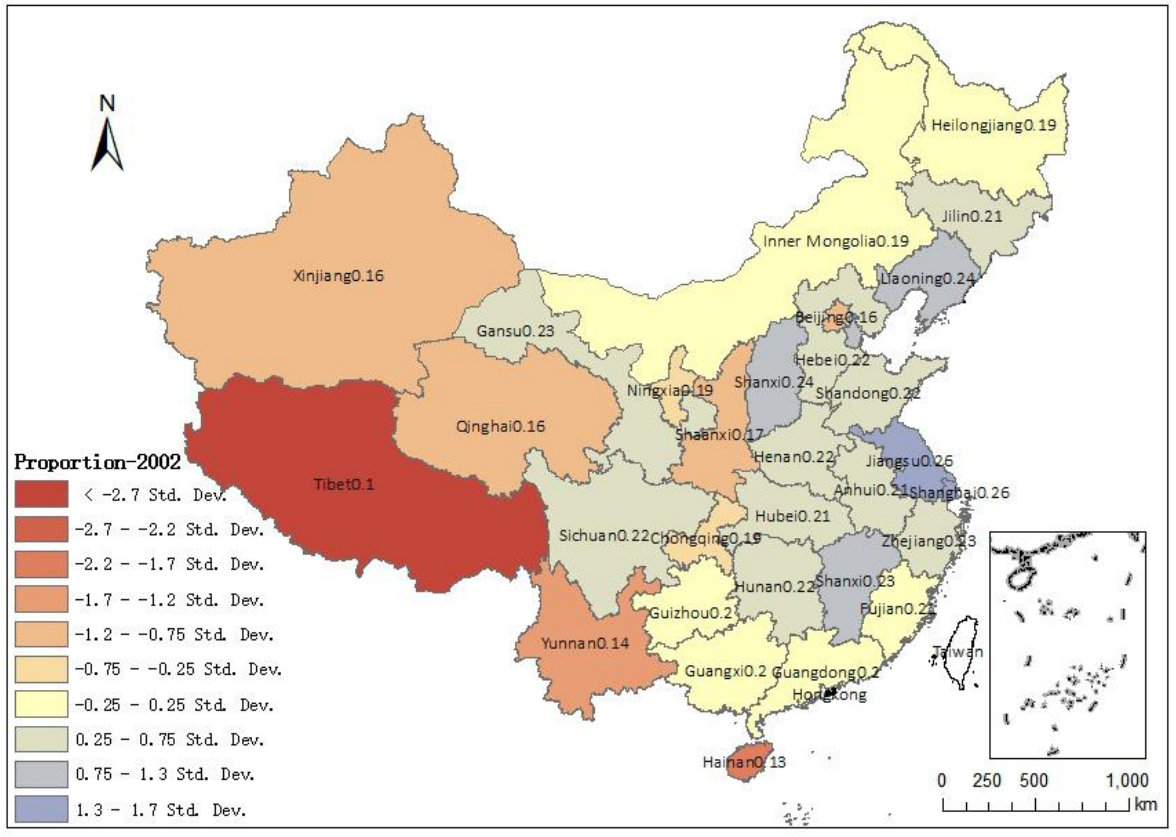

Figure 3.Urban industrial-construction proportion of provinces in China(2002).Sources:Calculated and drawn by the authors.

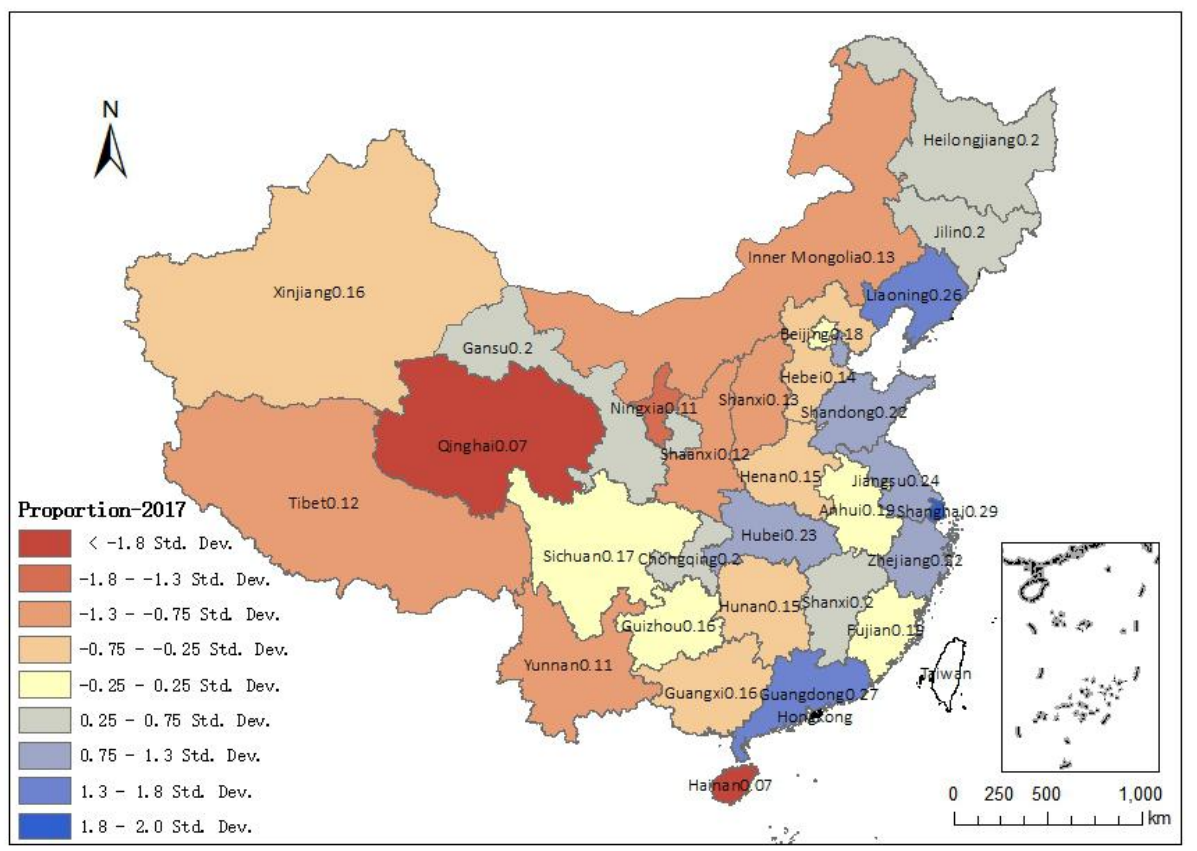

Figure 4. Urban industrial-construction proportion of provinces in China(2017).Sources:Calculated and drawn by the authors.

\subsection{Industrial land use at capital city levels}

We selected municipalities and capital cities for analysis. They are referred to as capital cities for the rest of the passage.The results observed at capital city levels are similar to the provincial findings (Table 3).Capital cities in China generally show decreasing proportions. Using $20 \%$ as the threshold to select hot spot capital cities: there were 17 hot spot capital cities in 2002, and only 9 capital cities in 2017. The maximum value and minimum value of proportion decreased. Capital cities with high proportions concentrated to eastern China. The change of top 5 capital cities in terms of industrial-construction 
proportion give similar evidence (Table 4) of the provincial analysis. Cities with historical manufacture and mining functions hold high proportions, like Taiyuan, Shenyang and Harbin in the first decade. In the second decade, cities in costal eastern China like Shanghai, Guangzhou and Nanjing took the top places.

\begin{tabular}{|c|c|c|c|c|}
\hline & \multirow[t]{2}{*}{ Capital cities } & \multirow[t]{2}{*}{ Provinces } & \multicolumn{2}{|c|}{ Proportion } \\
\hline & & & 2002 & 2017 \\
\hline \multirow{12}{*}{$\begin{array}{c}\text { Eastern } \\
\text { China }\end{array}$} & Beijing & Beijing & $15.61 \%$ & $17.95 \%$ \\
\hline & Tianjin & Tianjin & $23.45 \%$ & $24.37 \%$ \\
\hline & Shijiazhuang & Hebei & $21.79 \%$ & $5.99 \%$ \\
\hline & Shenyang & Liaoning & $27.97 \%$ & $25.82 \%$ \\
\hline & Shanghai & Shanghai & $25.8 \%$ & $28.8 \%$ \\
\hline & Nanjing & Jiangsu & $24.69 \%$ & $21.00 \%$ \\
\hline & Hangzhou & Zhejiang & $19.26 \%$ & $16.61 \%$ \\
\hline & Fuzhou & Fujian & $16.63 \%$ & $14.91 \%$ \\
\hline & Jinan & Shandong & $22.10 \%$ & $18.99 \%$ \\
\hline & Guangzhou & Guangdong & $24.56 \%$ & $26.85 \%$ \\
\hline & Nanning & Guangxi & $20.34 \%$ & $11.03 \%$ \\
\hline & Haikou & Hainan & $19.93 \%$ & $8.64 \%$ \\
\hline \multirow[t]{9}{*}{ Central China } & Taiyuan & Shanxi & $31.48 \%$ & $15.34 \%$ \\
\hline & Hohhot & Inner Mongolia & $18.12 \%$ & $8.06 \%$ \\
\hline & Changchun & Jilin & $21.43 \%$ & $23.66 \%$ \\
\hline & Harbin & Heilongjiang & $25.48 \%$ & $22.22 \%$ \\
\hline & Hefei & Anhui & $19.45 \%$ & $17.84 \%$ \\
\hline & Nanchang & Jiangxi & $21.00 \%$ & $19.45 \%$ \\
\hline & Zhengzhou & Henan & $16.13 \%$ & $8.94 \%$ \\
\hline & Wuhan & Hubei & $23.22 \%$ & $25.34 \%$ \\
\hline & Changsha & Hunan & $17.74 \%$ & $9.77 \%$ \\
\hline \multirow{9}{*}{$\begin{array}{c}\text { Western } \\
\text { China }\end{array}$} & Chongqing & Chongqing & $19.15 \%$ & $20.16 \%$ \\
\hline & Chengdu & Sichuan & $21.92 \%$ & $14.55 \%$ \\
\hline & Guiyang & Guizhou & $26.17 \%$ & $17.41 \%$ \\
\hline & Kunming & Yunnan & $15.69 \%$ & $12.30 \%$ \\
\hline & Xi'an & Shaanxi & $19.40 \%$ & $12.54 \%$ \\
\hline & Lanzhou & Gansu & $23.79 \%$ & $15.81 \%$ \\
\hline & Xining & Qinghai & $18.52 \%$ & $4.77 \%$ \\
\hline & Yinchuan & Ningxia & $20.19 \%$ & $9.77 \%$ \\
\hline & Urumqi & Xinjiang & $18.00 \%$ & $15.93 \%$ \\
\hline
\end{tabular}

Table 3.Urban industrial lands of capital cities in China(2002,2017).Source: Calculated and compiled by the authors. 


\begin{tabular}{|c|c|c|c|c|c|}
\hline Year & Rank 1st & Rank 2nd & Rank 3rd & Rank 4th & Rank 5th \\
\hline \multirow[t]{2}{*}{2002} & Taiyuan & Shenyang & Guiyang & Shanghai & Harbin \\
\hline & (0.315) & $(0.280)$ & $(0.262)$ & $(0.258)$ & $(0.255)$ \\
\hline \multirow[t]{2}{*}{2006} & Taiyuan & Changchun & Nanjing & Harbin & Chengdu \\
\hline & $(0.307)$ & $(0.270)$ & $(0.254)$ & $(0.234)$ & (0.229) \\
\hline \multirow[t]{2}{*}{2008} & Taiyuan & Nanjing & Changchun & Guangzhou & Harbin \\
\hline & (0.417) & $(0.257)$ & $(0.254)$ & $(0.241)$ & $(0.231)$ \\
\hline \multirow[t]{2}{*}{2011} & Taiyuan & Nanjing & Changchun & Chongqing & Harbin \\
\hline & $(0.273)$ & $(0.247)$ & $(0.240)$ & $(0.234)$ & $(0.231)$ \\
\hline \multirow[t]{2}{*}{2014} & Shanghai & Taiyuan & Tianjin & Nanjing & Changchun \\
\hline & $(0.251)$ & $(0.249)$ & $(0.236)$ & $(0.232)$ & $(0.232)$ \\
\hline \multirow[t]{2}{*}{2017} & Shanghai & Guangzhou & Shenyang & Wuhan & Tianjin \\
\hline & $(0.288)$ & $(0.268)$ & $(0.258)$ & $(0.253)$ & $(0.244)$ \\
\hline
\end{tabular}

Table 4.Capital cities ranking top 5 for industrial-construction proportion in China.Source:Calculated and complied by the authors.

\section{Model Specification and variables}

In order to examine the factors influencing industrial land use, panel regression models are conducted at the capital city level. With the panel data, the dimension of both time and cross sections are covered.25 capital cities are included in the data frame.

\begin{tabular}{ll}
\hline Region & Capital Cities \\
\hline Eastern China & Beijing,Tianjin,Shijiazhuang,Nanjing,Hangzhou,Fuzhou,Guangzhou,Nanjing, Haikou \\
Central China & Taiyuan,Hohhot,Changchun,Hefei,Nanchang,Zhengzhou,Wuhan,Changsha \\
Western China & Chongqing, Chengdu, Guiyang, Xi’an, Urumqi \\
\hline
\end{tabular}

Table 5.The 25 Capital cities for panel regressions in China.(Other excluded for incomplete data). Source:Complied by the authors.

A series of variables are selected to represent different factors on industrial lands during the new economic transformation. The economic development as well as the industry structure are included firstly. We select the actual utilization of foreign capital as well as base price for industrial lands to reflect the factor and land-extensive development mode. We select the local fiscal expenditure on technology and education to reflect the transferring of economic growth motivators. The model is specified as follows:

$$
\begin{aligned}
\text { PROPORTION }_{i t}= & \beta_{0}+\beta_{1} G_{\text {GDP }}+\beta_{2} \text { SECOND }_{i t}+\beta_{3} \text { TERTIARY }_{i t}+\beta_{4} \text { TECH_EDU } \\
& +\beta_{5} \text { LANDPRICE }_{i t} \beta_{6} \text { FINVEST } u_{i t}
\end{aligned}
$$

where i represents a capital city; PROPORTION refers to the urban industrial-construction proportion. Following regressions are conducted using R software. Definitions of variables are explained in Table 6.

Abbreviation Definitions




\begin{tabular}{ll}
\hline GDP & The gross domestic product of the capital city (Yuan; In) \\
SECOND & The proportion of second production (\%) \\
TERTIARY & The proportion of tertiary production (\%) \\
TECH_EDU & Local Fiscal Expenditure on technology and education (Yuan; In) \\
LANDPRICE & The base price for industrial lands(Yuan per square meter; In) \\
AFDI & Actual utilization of foreign capital (Dollar;ln) \\
\hline
\end{tabular}

Table 6.Definitions and abbreviations of variables.Source:Complied by the authors.

We generally conduct regressions of all the capital cities firstly. Model 1 is conducted with data of all these 25 capital cities in the first decade, namely in 2002,2006 and 2008. Model 2 contains data for all the 25 capital cities in the second decade, namely in 2011,2014 and 2017. Model 3 gives a general regression in the past two decades in 2002,2006,2008,2011,2014 and 2017.

\begin{tabular}{|c|c|c|c|}
\hline & $\begin{array}{c}\text { Model } 1 \\
(2002,2006,2008)\end{array}$ & $\begin{array}{c}\text { Model } 2 \\
(2011,2014,2017)\end{array}$ & $\begin{array}{c}\text { Model } 3 \\
(2002,2006,2008, \\
2011,2014,2017)\end{array}$ \\
\hline & Coefficient & Coefficient & Coefficient \\
\hline GDP & -0.30920 & $-13.12433 * * * *$ & $-5.44557 * * *$ \\
\hline SECOND & $0.71496 *$ & -0.59485 & $0.62864 *$ \\
\hline TERTIARY & $0.70242 * *$ & -0.48100 & $0.66053 * *$ \\
\hline TECH_EDU & -1.27840 & $9.54066 * * * *$ & $3.07872 * *$ \\
\hline LANDPRICE & 5.62286 & 2.81707 & -1.24108 \\
\hline AFDI & $-1.86846 * *$ & -0.73927 & $-0.84366^{*}$ \\
\hline R-squared & 0.30428 & \multirow[t]{2}{*}{0.37065} & 0.24832 \\
\hline \multicolumn{2}{|c|}{ Note: ${ }^{*} p<0.1, * * p<0.05, * * * p<0.01$} & & \\
\hline
\end{tabular}

Table 7.Panel estimation results of 25 capital cities in different periods.Sources:Calculated and complied by the authors using $\mathbf{R}$ language.

According to the results of Model 1, SECOND and TERTIARY have significantly positive relationship with PROPORTION. Besides, GDP as well as AFDI, show significantly negative relationship with PROPORTION. While the results of Model 2 in the second decade indicate different results. GDP and TECH_EDU show significant relationship with the PROPORTION, which is not seen in Model 1.Besides, SECOND, TERTIARY , as well as AFDI, are not significant in model 2. Comparing the value of the coefficient of Model 1 and Model 2, we could see that the absolute value of the coefficient of GDP and TECH_EDU increased greatly from the first decade to the second one, while the others decreased in absolute values.

We conducted two more regressions after dividing the capital cities into 2 groups: one group includes the capital cities in eastern China, the other group consists of capital cities in middle and western China. Table 8 shows the different results between different regions. For capital cities in eastern China, Model 4 indicates a significant positive relationship between TERTIARY and PROPORTION. Model 5 shows a significant negative relationship between LANDPRICE and PROPORTION, which suggests the relatively low industrial price would contribute to the expansion of industrial lands. Both model show negative coefficients between AFDI and PROPORTION, which is out of expectation. 


\begin{tabular}{|c|c|c|c|}
\hline $2002,2006,2008$ & Model3 & Model 4 & Model 5 \\
\hline \multirow[t]{2}{*}{$2011,2014,2017$} & ALL & Eastern & Middle and western \\
\hline & Coefficient & Coefficient & Coefficient \\
\hline GDP & $-5.44557 * * *$ & -1.96139 & $-5.50288 * *$ \\
\hline SECOND & $0.62864 *$ & 0.76883 & 0.16075 \\
\hline TERTIARY & $0.66053 * *$ & $0.89118^{*}$ & 0.11136 \\
\hline TECH_EDU & $3.07872 * *$ & -0.50557 & $4.86305 * * *$ \\
\hline LANDPRICE & -1.24108 & 2.65499 & $-8.90311 * * *$ \\
\hline AFDI & $-0.84366^{*}$ & -1.06994 & -0.92731 \\
\hline R-squared & 0.24832 & 0.35023 & 0.36841 \\
\hline Note: ${ }^{*} \mathrm{p}<0.1,{ }^{*}{ }_{\mathrm{p}}$ & $=0.01, * * * * 0$. & & \\
\hline
\end{tabular}

Table 8. Panel estimation results of 25 capital cities in different regions.Sources:Calculated and complied by the authors using $\mathbf{R}$ language.

To give more detailed analysis in the second decade, we conducted Model 6 and Model 7.The results are shown in Table 9.Model 6 on capital cities in eastern China in the second decade shows a significantly positive coefficient of TECH_EDU and a significantly negative coefficient of GDP. These results agree with Model 2. Model 7 on capital cities in middle and eastern China has a significantly negative coefficient of AFDI, and similar significant coefficient of GDP and TECH_EDU of Model 6.

\begin{tabular}{llll}
\hline 2011,2014,2017 & Model2 & Model 6 & Model 7 \\
& ALL & Eastern & Middle and western \\
& Coefficient & Coefficient & Coefficient \\
\hline GDP & $-13.12433^{* * * *}$ & $-12.59746^{* *}$ & $-10.42009 * * *$ \\
SECOND & -0.59485 & -0.45265 & -0.89980 \\
TERTIARY & -0.48100 & -0.12900 & -0.92314 \\
TECH_EDU & $9.54066^{* * * *}$ & $9.26385^{*}$ & $8.67365^{* * *}$ \\
LANDPRICE & 2.81707 & 3.81891 & -7.90302 \\
AFDI & -0.73927 & -0.20264 & $-1.17991^{*}$ \\
& & & \\
R-squared & 0.37065 & 0.41862 & 0.55727 \\
Note: $* p<0.1, * * p<0.05, * * * p<0.01, * * * * 0.001$. & & \\
\hline
\end{tabular}

Table 9. Panel estimation results of 25 capital cities in different regions in the second decade.Sources:Calculated and complied by the authors using $\mathbf{R}$ language. 


\section{Findings and Discussions}

We get the following findings from the results shown in Table 7-9.Generally speaking, GDP, LANDPRICE as well as AFDI show negative relationships with PROPORTION, while SECOND, TERTIARY and TECH_EDU show positive relationships, but the effects and coefficients can differ in different periods and regions.

(1) GDP shows significantly negative effects with PROPORTION in all models. This confirms that cities with higher GDP values are more likely to have lower industrial-construction proportion.

(2) SECOND and TERTIARY, both indicate the industry structure of an economy, show positive relationships with PROPORTION in the first decade and negative relationships with PROPORTION in the second decades. This agrees with the discussion before, that the industry development were relying on industrial lands in the initial stage, while further development would have less reliance on industrial sites. The negative relationship of second industry suggests that the integration of the second industry are less land-extensive in the second decade.

(3) TECH_EDU shows negative relationships in Model 1 and Model 4, while the significant positive relationships with PROPORTION are shown in other models. This suggests that in eastern regions, fiscal expenditures on technology and education can possibly reduce the value of proportion, while the effect is not apparent in other regions. One possible reason is that scientific expenditures are often used for the technologies in the production process, which directly correlates with the industrial land use.

(4) LANDPRICE is more likely to affect PROPORTION in the capital cities in the middle and east China than in the eastern China. The absolute values of the coefficient are bigger in the middle and western China. This result suggests that reliance on the relatively low base price for industrial lands to establish industry parks in cities in middle and western China still exists.

(5) The significant negative effect of AFDI is unexpected. We investigated the coefficient of other two simple regressions: the first one only contains the area of industrial lands and AFDI, the other one deals directly with the area of construction lands and AFDI. Significant positive relationships were shown in both regressions. Therefore, the expansion and development of industrial lands and construction lands are both positively related with the AFDI, which is already discussed by scholars. However, our analysis support that industrial-construction proportion is negatively related with AFDI. This could be explained by the research of Lin(2008) that the foreign investment are more related with more green space and more advanced industry structure. The demands might contradict with high proportions of industrial lands.

\section{Conclusions}

Among developing world, the past decades in China have seen extensive industrial lands use as one of the motivator for high-speed development. As China is slowing down the growth rate and turning to technology-driven growth, industrial lands deserve new investigation. Main conclusions of our study are as follows.First, the expansion of industrial lands has slowed down in the past two decade and the national urban industrial-construction proportion generally decreased to about $20 \%$. Using industrialconstruction proportion and the location quotient for industrial land as indicators, hot spot provinces and capital cities are concentrating to eastern China. Secondly, GDP is negatively correlated with proportion, while both second and tertiary industry have negative relationships with proportions in the second decade. Industrial land prices are positive related to proportion in eastern regions and negative related in central and western China. Foreign investment has negative relationship with proportions, which is out of expectations. The fiscal expenditures on technology and education show generally positive relationships with proportions. The significant negative relationship was not observed.Our results provide investigation of the influencing factors on industrial lands and help understand the future of industrial lands 
development. The role of foreign investment and fiscal expenditure on technology and education are new findings.

We make three suggestions for policy-makers in China and other developing countries.

(1)Attitudes towards industrial lands and policies related should consider social and economic factors for the first place. Economic performance is most strongly correlated with industrial lands. For a developing economy like China, both secondary and tertiary sectors are positive related with industrial lands. Therefore, hasty actions to turn to service sectors and abandon industrial lands for economic profits would be unwise.

(2)Second, globalization force to expand industrial lands might be strong and positive in former years, but the effect could be negative in general. Foreign investment could be critical for other variables like green space and be negative related with high industrial-construction proportion. For cities and regions trying to attract foreign investment and establish industrial parks, attention should be paid to the soft environment there.

(3) Although technology is treated as powerful motivator for an economy, the expenditure on technology and education do not assure the decrease of industrial lands in short time. Regions with higher economic development level are more likely to reduce industrial land uses with technology and education expenditures by the governments.

However, there are several limitations to this study. The scope of our data is limited to 2002 to 2017 and the analysis is conducted only on capital cities. Some capital cities were excluded for lack of important data.We did not carried out research on prefecture city level in the past decades because of limited available. Besides, the role of technology, education, foreign investment and other variables like green space also deserve deep research in the future. Factors influencing industrial lands into other uses also make a good research subject.

\section{References}

1. Chen, R. et al. (2014) 'The impact of rural out-migration on land use transition in China: Past, present and trend', Land Use Policy, 40, pp. 101 - 110.

2. Chen, Wei et al. (2019) 'Exploring the industrial land use efficiency of China's resource-based cities', Cities, 93(3), pp. 215 - 223.

3. Daniel Bell. 'The Coming of the Post-Industrial Society', Journal of the Operational Research Society 31.1(1974):83-84.

4. Gao, Y. and Ma, Y. (2015) 'What is absent from the current monitoring: Idleness of rural industrial land in suburban Shanghai',Habitat International,49,pp.138 - 147.

5. He, C., Huang, Z. and Wang, R. (2014) 'Land use change and economic growth in urban China: A structural equation analysis', Urban Studies, 51(13), pp. 2880 - 2898.

6. Huang, L. et al. (2020) 'Characterizing spatial patterns and driving forces of expansion and regeneration of industrial regions in the Hangzhou megacity, China', Journal of Cleaner Production, 253, p. 119959.

7. Huang, Z. et al. (2015) 'Urban land expansion under economic transition in China: A multi-level modeling analysis', Habitat International, 47, pp. $69-82$. 
8. Iammarino, S. and McCann, P. (2006) 'The structure and evolution of industrial clusters: Transactions, technology and knowledge spillovers', Research Policy, 35(7), pp. 1018 - 1036.

9. Li, X. et al. (2020) 'Transition from factor-driven to innovation-driven urbanization in China: A study of manufacturing industry automation in Dongguan City', China Economic Review, 59(135).

10. Lin,Q.(2008) 'Protections for investors and actual utilization of foreign capital:A comparative study between Guangzhou Development Zone and Suzhou Industrial Park', South China Review,01,pp.6477.(In Chinese)

11. Liu,Z. and Zhu,B.(2012) 'Industrial land adjustment in new code for classification of urban land use and planning standards of development land', Planners,2,pp.29-33.

12. Mao, Z. and Zuo, Y.(2007) 'Study on contribution rate of land to the secondary and service industry growth', China Land Science,21(June 2007),pp. 59-63.(In Chinese)

13. Needham, B., Louw, E. and Metzemakers, P. (2013) 'An economic theory for industrial land policy', Land Use Policy, 33, pp. 227-234.

14. Qiu, R., Xu, W. and Zhang, J. (2015) 'The transformation of urban industrial land use: A quantitative method', Journal of Urban Management, 4(1), pp. 40-52.

15. Qu, Y. et al. (2019) 'Understanding rural land use transition and regional consolidation implications in China', Land Use Policy, 82(January), pp. 742 - 753.

16. Shu, H. and Xiong, P.ping (2019) 'Reallocation planning of urban industrial land for structure optimization and emission reduction: A practical analysis of urban agglomeration in China's Yangtze River Delta', Land Use Policy, 81(October 2018), pp. 604 - 623.

17. Wei, Y. H. D. (2012) 'Restructuring for growth in urban China: Transitional institutions, urban development, and spatial transformation', Habitat International, 36(3), pp. 396 - 405.

18. Wen W.,Che N,.Zhou D, Y.et al.(2017) 'The interaction between industrial land supply and industrial transformation in Beijing', Resources Science,39(9), pp.1702-1711.(In Chinese)

19. Wu, Q. et al. (2018) 'The de-industrialization, re-suburbanization and health risks of brownfield land reuse: Case study of a toxic soil event in Changzhou, China', Land Use Policy, 74(February 2017),18794.

20. Wu, Y. et al. (2014) 'Industrial land price and its impact on urban growth: A Chinese case study', Land Use Policy, 36, pp. 199-209.

21. Wu, Y. et al. (2016) 'Urban growth dilemmas and solutions in China: Looking forward to 2030', Habitat International, 56, pp. 42 - 51.

22. Xie, H. et al. (2016) 'Measuring the sustainable performance of industrial land utilization in major industrial zones of China', Technological Forecasting and Social Change, 112, pp. 207 - 219.(In Chinese)

23. Yang,Y. et al. (2019) 'Does the land use structure change conform to the evolution law of industrial structure? An empirical study of Anhui Province, China', Land Use Policy, 81(June 2018), pp. 657 667.

24. Yue, W., Liu, Y. and Fan, P. (2013) 'Measuring urban sprawl and its drivers in large Chinese cities: The case of Hangzhou', Land Use Policy, 31, pp. 358-370. 
25. Zhang, J. et al. (2019) 'Spatial distribution and influential factors of industrial land productivity in China's rapid urbanization', Journal of Cleaner Production, 234, pp. 1287 - 1295.

26. Zheng, X. et al. (2014) 'Performance evaluation of industrial land policy in China', Sustainability (Switzerland), 6(8), pp. $4823-4838$.

27. Zhu, J. (2000) 'The impact of industrial land use policy on industrial change', Land Use Policy, 17(1), pp. $21-28$. 